\title{
$\begin{array}{ll}\text { Research Square } & \text { Preprints are preliminary reports that have not undergone peer review, } \\ \text { They should not be considered conclusive, used to inform clinical practice, }\end{array}$ or referenced by the media as validated information. \\ Clinical Characteristics of SARS-CoV-2 by Re- infection Vs. Reactivation: A Case Series From Iran
}

\author{
Mostafa Salehi-Vaziri
}

Pasteur Institute of Iran

\section{Tahmineh Jalali}

Pasteur Institute of Iran

\section{Behrokh Farahmand}

Pasteur Institute of Iran

\section{Fatemeh Fotouhi}

Pasteur Institute of Iran

\section{Mohammad Banifazl}

Iranian Society for support of patients with infectious diseases

\section{Mohammad Hassan Pouriayevali}

Pasteur Institute of Iran

Mona Sadat Larijani

Pasteur Institute of Iran

Neda Afzali

Pasteur Institute of Iran

Amitis Ramezani ( $\square$ amitisramezani@hotmail.com )

Pasteur Institute of Iran https://orcid.org/0000-0003-3502-8524

\section{Original Article}

Keywords: COVID-19, SARS-CoV-2, re-infection, reactivation

Posted Date: February 5th, 2021

DOI: https://doi.org/10.21203/rs.3.rs-185401/v1

License: (c) (i) This work is licensed under a Creative Commons Attribution 4.0 International License.

Read Full License

Version of Record: A version of this preprint was published at European Journal of Clinical Microbiology \& Infectious Diseases on March 18th, 2021. See the published version at https://doi.org/10.1007/s10096021-04221-6. 


\section{Abstract}

Purpose: COVID-19 immunity in infected individuals may not be persistent. The specific response wanes in patients who have recovered from this infection. Nevertheless, it has not been fully understood whether true re-infection occurs or the viral reactivation.

Methods: In this study, we investigated three COVID-19 patients who represented the symptoms after recovery. Chest CT scan was applied to assess the patients along with the viral samples from oropharyngeal/nasopharyngeal which were subjected to RT-PCR. The viral genome sequencing was applied where possible to distinguish possible re-infection or latent reactivation. Moreover, COVID-19 specific antibodies available data were evaluated in each incidence.

Results: The second episode of SARS-CoV-2 infection was different among the investigated subjects who experienced an interval between positive PCR tests ranged between 63 and 156 days. The disease presentation was less or more severe in the second infection. All cases were found IgG positive in the reinfection phase. The sequencing of SARS-CoV-2 sample obtained from two cases revealed a D614G mutation of $S$ gene from the second isolated sample strengthens the case for the re-infection.

Conclusions: The possibility of re-infection and reactivation could have significant effect on clinical implications and also vaccination. Our data supports clear warning of SARS-CoV-2 continuous circulation potency among the populations in spite of herd immunity either with natural infection or vaccination. This issue is critical in term of the patients, clinical investigate and viral transmission.

\section{Introduction}

COVID-19 pandemic has affected over 90 million infected with more than two million deaths worldwide [1]. The high contagion of SARS-CoV-2 by droplets and other contact routes has resulted in outbreaks [2].

According to the studies which have been conducted on people who once caught COVID-19, a healthy immune response developed with both immunity arms, antibodies and T cells [3-6].

After the clearance of SARS-CoV-2 virus, that immune response is supposed to block a second infection due to generated memories against the virus. Considering this fact, people who recover from the infection should be protected from another possible infection for at least some amount of time, however, the length of this time has not been identified, yet $[7,8]$. Some other viruses, the first infection could result in lifelong immunity, however, short-lived immunity is the outcome of seasonal coronaviruses $[9,10]$.

The exact mechanism of provided protection against SARS-CoV-2 has not been known, nor have the required levels of humoral or cellular responses been fully understood. Some probable factors associated with the re-infection are age, the health level of immunity system, correlated antibody and possible virus mutations. [11]. 
Some studies have also shown that COVID-19 with mild presentation induce weaker immune responses which might provide short protection rather than severe form of the infection [12,13]. Most infected SARS-CoV-2 individuals reach an antibody response during day 10 to day 21 post infection. Mild cases display this response after four weeks and in a minority of cases, IgM and IgG are not detectable [14-16]. Neutralizing antibodies are generated after infection and their titers start to decline 2 months after the acute phase of the infection according to some researches. On the other hand, some studies detected antibodies for 6 months after the infection [17-19]. The second infection could be as the result of antibody faint or the viral sequence mutation especially in spike gene.

SARS-CoV-2 reactivation cases data are limited. COVID-19 therapy with curative and eradicative effect is not currently available. Reactivation seems to be more probable in those who suffers from an underlying condition or immune suppression. Subjects who are susceptible to reactivation are those with compromised immune systems such as dialysis patients or patients undergoing immune suppressive therapy[20, 21].

Therefore, fundamental question among the present pandemic is how long the immune responses against SARS-CoV-2 protect the host from re-infection or reactivation [9]. Moreover, a key question for COVID-19 is whether true re-infection occurs or not. It is really important to be sure about the negative cases in term of the test accuracy which brings the concern of SARS-CoV-2 reactivation in cases who got the infection and recovered. Moreover, the re-infection of the disease in the number of reported cases raises the consideration of vaccine efficacy against COVID-19 [22, 23].

Hereby, we report a case series of patients with COVID-19 who experienced reactivation or re-infection after negative PCR tests.

\section{Materials And Methods}

In this study, COVID-19 suspected re-infected cases who were referred to COVID-19 National Reference laboratory at Pasteur Institute of Iran, were investigated. COVID-19 was assessed upon admission based on the COVID-19 diagnosis and treatment flowchart in Iran (3rd edition) [24]. The oropharyngeal/nasopharyngeal swab specimens, in viral transport media (VTM), were assessed in the laboratory. Viral RNA was extracted using a QIAcube HT system with a QIAamp 96 Virus QIAcube HT Kit, according to the manufacturer's instructions. RealTimeReverse-transcription PCR (Real Time RT-PCR) assay was performed using 2019-nCoV Nucleic Acid Diagnostic kit (Sansure biotech, Changsha, China), according to the manufacturer's protocol. Serology tests were also employed to assess humoral responses SARS-CoV-2 IgM Capture kit (cat no: PT-CoV-2-IgM Cap-96 [sensitivity 70\%, specificity: 75\%] Pishtazteb, Iran) and SARS-CoV-2 IgG kit (cat no: PT-CoV-19 IgG-96, [sensitivity 78\%, specificity: 91\%] Pishtazteb, Iran) were applied according to the provided protocol.The viral sample from each patient was finally subjected to sequencing to assess probable mutation. Partial N (466bp) and S (899bp) fragments were amplified using RT-PCR one step RT-PCRKit (biotechrabbit, Germany) according to Tab.1. All PCR 
products were analyzed by gel electrophoresis and were mostly confirmed by bidirectional Sanger sequencing. Due to the low quality of samples, we could only sequence it partially.

Patients' confirmed recovery was described as two RT-PCT tests with negative result with 24 hours interval. These mentioned methods were applied the same for both admission steps.

\section{Case Presentations}

All the procedures were in accordance with the ethical standards of the responsible committee on human experimentation of Pasteur Institute of Iran under IR.PII.REC.1399.009 ethical code and also with the Helsinki Declaration.

Three COVID-19 confirmed cases by CT scan or RT-PCR in Pasteur Institute of Iran in March and April 2020, who presentedCOVID-19 symptoms some months after negative RT-PCR were studied (Tab.2). The patients' symptoms resolution was achieved in all cases before the second symptoms initiation. None of the investigated subjects had underlying disease. Most importantly, case\#1 had exposed to a confirmed infected family member and case\#3 had contact to a confirmed colleague at workplace before they caught the disease in both episodes of the incidence. Only case \#2 was not exposed to any confirmed patient. Furthermore, they did not catch the infection from the same source in each incidence and all cases fully recovered after the second episode.

The first case, a 32-year old woman, had an interval of 63 days between the two infections. The COVID-19 infection was confirmed by bilateral and peripheral ground-glass opacities in chest CT. The antibody titration was achieved positive by the rapid test (sensitivity $72 \%$, specificity: $76 \%$ ) for IgM (At the time of second infection, IgG titration was assessed as $4.89 \mathrm{AU} / \mathrm{ml}$ which after two months turned to a significant raise (over ELISA reader standard range). The disease presentation was similar in both incidences, however with more severe symptoms in the second time. The viral sequencing revealed a D614G mutation of S gene from the second isolated sample (Fig.1).

The second case, a 54-year old man whose infection was confirmed by RT-PCR. He recovered from the disease after 22 days with negative RT-PCR. After an interval of 156 days, the symptoms of the second infection appeared with less severity and gastrointestinal presentation. IgM and IgG were detected in the first incidence and he was being followed up to the second virus presentation. In the whole duration between two incidences, IgG test was positive. Antibody titration at the time of second infection showed that IgG level was $5.25 \mathrm{IU} / \mathrm{ml}$ which increased to $27.5 \mathrm{IU} / \mathrm{ml}$ after about two weeks. The viral sequencing was obtained for $\mathrm{N}$ protein which showed no difference of the virus clade in both incidences (Fig.2). Both sequences had L139L non-synonymous mutation, novel mutation in nucleotide position 28688 . S portion sequencing was not achieved due to the low viral load.

A 42-year man was the third subject whose infection was confirmed by RT-PCR and bilateral and peripheral ground-glass opacities chest CT. He was fully recovered after the first infection and his RT-PCR was negative after 22 days. However, the antibody titration was not applied. He showed the second 
COVID-19 infection with 111days of interval. The IgG titration was $17.5 \mathrm{IU} / \mathrm{ml}$ which decreased to 6.5 $\mathrm{IU} / \mathrm{ml}$ after almost two weeks. His clinical symptoms were similar with more severe diarrhea in the second presentation step. In this case, the Cycle threshold (Ct) was high so, the viral sequencing was not achieved. Moreover, the viral sequencing also revealed a D614G mutation of $S$ gene from the second obtained sample (Fig.1).

The serology tests of the cases were also investigated and all three cases were found IgG positive at the re-infection incidence.

\section{Discussion}

The level of protective immunity mounted by SARS-CoV-2 infection is not currently known. Therefore, the re-infection probability has been found notably considerable. In this study, we reported 3 cases with suspicious for COVID-19 re-infection. The serology tests revealed that specific SARS-CoV-2 IgG presence is not enough to protect the second viral infection according to the findings. The disease presentation could be less or more severe in the re-infected patients. Moreover, the symptoms might be similar or different in each incident.

Recently, there have been few re-infected COVID-19 case reports. The first case was reported from Hong Kong, a 33-year man, who caught COVID-19 firstly in March with mild symptom presentation. After 4 months and a half, he was found PCR positive with high viral load but asymptomatic. Antibody seroconversion was recorded on the second infection. This might be according to the short lived immunity which faints after a while [25].

The other reported case, a 25-year man from Nevada, the U.S. was confirmed to be infected with the SARS-CoV-2 twice. The interval between two infections was found 48 days. Surprisingly, he developed more serious disease in the second time including myalgia, cough and shortness of breath and he required oxygen support. The data shows that both patients' samples had genetic discordance which highlights the re-infection possibility[26].

Another case report from Brazil, was a nurse who caught COVID-19 infection first in May, 2020 with no specific underlying disease but only sporadically headache. Following the recovery and 38 days with no symptoms, late in June, 2020 she faced severe headache, malaise, myalgia, fatigue, and fever feeling which developed with diarrhea and coughing. Her SARS-CoV-2 RT-PCR test was positive on 5th day of the symptoms. Nevertheless, the SARS-CoV-2 antibody detection rapid test (IgG/lgM) was negative. IgG was detected on 19th and 33rd days after the new onset of symptoms [27].

The other case report was a 20-year-old woman from Israel, diagnosed with Covid-19 in April, 2020. She presented mild symptoms including fever and cough, with no respiratory distress and was confirmed by a positive nasopharyngeal PCR test. She cleared the virus in May. After three months, she became positive in August although she had no symptoms. Viral serology in August revealed positive SARS-Covid-2 IgG antibodies [28]. 
In the case report from Ecuador, the genome sequencing was found different in two incidents. The subject firstly presented mild infection in May whereas the re-infection led to a moderate presentation [28, 29]. SARS-CoV-2 re-infection with worse presentation which results in oxygen support requiring and hospitalization raises concerns re-infection [30].

United States and Ecuadorboth reportedre-infection cases who experienced increased symptom severity during second infection. The infected cases from Belgium, Hong Kong and the Netherlands, did not present more severe symptoms. There have been three possible explanations for the patient's more serious symptoms including a higher viral load in the re-infection phase than the first infection, a more virulent version of the virus as the cause of the second incident and the developed antibodies which could result in the subsequent worse infection [30,31].

In the study from Hong Kong, after two genome sequencing on respiratory specimens during two episodes of a COVID-19 infected patients, the results showed that the firstly viral genome and the second one were belonged to different virus clades with a stop codon at position 64 of orf 8 which led to a truncation of 58 amino acids. They concluded that serological and genomic analyses were strong clues for the re-infection instead of persistent viral shedding. The patient from Hong Kong did not develop Covid-19 antibodies in first disease whereas the second presentation led to antibodies detection. The viral genomes of these studies from Hong Kong, Nevadaand Ecuador were sequenced to determine that the two infections as separate events which resulted differently [28, 29, 32, 33]. Coppolla et al, reported a PCR-confirmed COVID-19 patient who experienced viral reactivation with milder symptoms after 43 days interval and negative PCR. This case had dyslipidemia and chronic ischemic heart disease as underlying diseases [20].

The other SARS-CoV-2 reactivation case was a 55-year-old female suffering from Philadelphia chromosome-positive, CD20-positive B-ALL, asthma, coronary artery disease and diabetes. After two negative PCR tests and discharge, she re-presented the infection with more severe symptoms. Considering the short time frame, reactivation seems more rational than re-infection. This highlights the risks of recently recovered COVID-19 patients who are on the treatment of immunosuppressive therapy and raises critical questions about the reactivation of SARS-CoV-2 [34]. Based on the observation they suggested that recovered patients must be considered as the carriers of the virus and therefore an additional round of follow up and isolation are needed [20].

There was a reported case from Italy, who recovered from COVID-19 with positive serology. This 69-yearold woman was suffering from type 2 diabetes mellitus and urinary tract neoplasm. She was followed up for one month with six negative PCR tests. Nevertheless, she presented a second IgM seroconversion along with a positive RT-PCR after exposure to the virus [35].

More recently, new SARS-CoV-2 variant in Brazil has reported after the two mutated strains of the virus which were discovered in the U.K. and South Africa. The newly reported variant of the virus belongs to the B.1.1.248 strain which contains 12 mutations in the spike protein. Although viruses are naturally supposed to mutate, the SARS-CoV-2 variants are shown to be more transmissible in comparison with the 
original which started the pandemic. Therefore, this could result in higher numbers of serious infections and probable additional deaths [36].

Among the investigated cases in our study, sequencing also suggest that two cases, No\#1 \& No\#3, infected in two separated steps according to the viral mutation (Fig. 1). The amino acid change in the spike protein of the virus, D614G, has emerged early during the pandemic as the viruses harboring this mutation are now dominant in many places worldwide [37]. There have been some evidences that the rapid spread of G614 was due to its more infectious potency than D614 and a higher levels of viral RNA has been assessed in the clinical samples from G614 infections[38, 39].

The recent study by usage of pseudovirus showed that $7 \%$ of convalescent sera obtained from recovered COVID-19 subjects contained reduced serum neutralizing activity against 614G in comparison with 614D [38]. According to the time of the first infection, the predominant circulating virus in Iran was D614 which initiated from China. After few months the G614 type was also found in Iran from the European countries. Therefore, we can assume that the second virus was different in the second infection occurrence and reinfection was probable occurrence. Moreover, the symptoms were more serious in the second incidence.

The other case, patient No\#2, experienced 157 days of interval between the two incidences and was confirmed negative by RT-PCR. This patient was being followed up in every scene of the disease until he fully recovered. Interestingly, the IgG test was detected monthly in the period between to incidences. Although IgG level raised in the second infection and the symptoms appeared again, the virus type was the same in both infections suggesting that re-activation of the infection occurred (Table 2). As Fig. 2 shows, the $\mathrm{N}$ sequencing shows a non-sense mutation $\mathrm{T}: \mathrm{C}$ based on the similarity between the symptoms and low severity in the second infection, reactivation seems more logical in this case. With the experience of two infection episodes by two SARS-CoV-2 positive specimens separated by a period of 157 days and also the resolution of symptoms with negative RT-PCR, reactivation incidence was more probable.

There has recently been an increasing number of COVID-19 patients with the second episode of the infection in Iran. It seems that the patients who experience the second infection, have high $\mathrm{Ct}$ and low viral load. The other important issue is that all the investigated cases in this study were IgG positive at the second infection time with no specific underlying disease. Although, the applying serological platforms are different worldwide and the comparison is not rational, the protection potency of IgG is the fundamental matter. The patients from the USA and Ecuador who had more serious symptoms in reinfection phase strongly highlights this issue. In other cases, that experience mild presentation in the second episode, it is not fully understood that present antibodies play a role or not.

\section{Conclusion}

We presented three cases of possible SARS-CoV-2 re-infection or re-activation of latent virus, based on clinical and laboratory evidence. 
The reported cases from different countries has raised the concern that re-infection or reactivation of SARS-CoV-2 affect the efficacy of emerging vaccines. It had been generally thought that once the infection occurs, immune response could prevent a second infection in the same person. Nevertheless, the possibility of re-infection which seems is growing worldwide has significant effect on clinical implications and also vaccination. The serology tests revealed that specific SARS-CoV-2 IgG presence is not enough to protect the second viral infection. According to the fact that reinfection has happened in cases who had developed IgG, the neutralizing potency of the produced antibodies are unknown. There is also another consideration about new viral mutations which are not recognized by existing immunity. Although the distinct between the re-infection and reactivation of SARS-CoV-2 is challenging, these results might be clues of SARS-CoV-2 potency to circulate continuously between the populations despite herd immunity either with natural infection or vaccination. We can conclude that asymptomatic patients in the second infection could strongly impose a threat to the society. Therefore, PCR test must be considered to determine the second incidence which is really critical in term of the patients, clinical investigate, vaccination study and viral transmission.

\section{Declarations}

\section{Funding}

This work was supported by Pasteur Institute of Iran [grant number 1158].

\section{Conflict of Interest}

Authors declare no potential conflict of interest that could negatively influence the study.

\section{Ethics approval}

The study was approved by Pasteur Institute of Iran Ethical committee under IR.PII.REC.1399.009 ethical code.

\section{Acknowledgment}

We do appreciate Pasteur Institute of Iran for financial support of this study.

\section{References}

1. Epaulard O, Adam L, Poux C, et al. Macrophage- and neutrophil-derived TNF-alpha instructs skin langerhans cells to prime antiviral immune responses. Journal of immunology (Baltimore, Md : 1950). 2014;193(5):2416-26.

2. Hung IF-N, Cheng VC-C, Li X, et al. SARS-CoV-2 shedding and seroconversion among passengers quarantined after disembarking a cruise ship: a case series. Lancet Infect Dis. 2020;20(9):1051-60. 
3. Sewell HF, Agius RM, Stewart M, et al. Cellular immune responses to covid-19. BMJ. 2020;370:m3018.

4. Changes in antibodies and RNA shedding during early SARS-CoV-2 infection [press release]. News Medicla Life Science, May 22, 20202020.

5. Udugama B, Kadhiresan P, Kozlowski HN, et al. Diagnosing COVID-19: The Disease and Tools for Detection. ACS Nano. 2020;14(4):3822-35.

6. Zhou G, Zhao Q. Perspectives on therapeutic neutralizing antibodies against the Novel Coronavirus SARS-CoV-2. International Journal of Biological Sciences. 2020;16:1718-23.

7. Siracusano G, Pastori C, Lopalco L. Humoral Immune Responses in COVID-19 Patients: A Window on the State of the Art. Frontiers in Immunology. 2020;11(1049).

8. Catanzaro M, Fagiani F, Racchi M, et al. Immune response in COVID-19: addressing a pharmacological challenge by targeting pathways triggered by SARS-CoV-2. Signal Transduction and Targeted Therapy. 2020;5(1):84.

9. Edridge AWD, Kaczorowska J, Hoste ACR, et al. Seasonal coronavirus protective immunity is shortlasting. Nature Medicine. 2020.

10. Sofian M, Velayati AA, Banifazl M, et al. SARS-CoV-2, a virus with many faces: a series of cases with prolonged persistence of COVID-19 symptoms. Wiener medizinische Wochenschrift (1946). 2020:1-4.

11. To KK-W, Hung IF-N, Ip JD, et al. Coronavirus Disease 2019 (COVID-19) Re-infection by a Phylogenetically Distinct Severe Acute Respiratory Syndrome Coronavirus 2 Strain Confirmed by Whole Genome Sequencing. Clinical Infectious Diseases. 2020.

12. García LF. Immune Response, Inflammation, and the Clinical Spectrum of COVID-19. Frontiers in Immunology. 2020;11(1441).

13. Shi Y, Wang Y, Shao C, et al. COVID-19 infection: the perspectives on immune responses. Cell Death \& Differentiation. 2020;27(5):1451-4.

14. Woelfel R, Corman VM, Guggemos W, et al. Clinical presentation and virological assessment of hospitalized cases of coronavirus disease 2019 in a travel-associated transmission cluster. medRxiv. 2020:2020.03.05.20030502.

15. OKBA NMA, Muller MA, Li W, et al. SARS-CoV-2 specific antibody responses in COVID-19 patients. medRxiv. 2020:2020.03.18.20038059.

16. Zhao J, Yuan Q, Wang H, et al. Antibody responses to SARS-CoV-2 in patients of novel coronavirus disease 2019. Clinical infectious diseases : an official publication of the Infectious Diseases Society of America. 2020.

17. Long Q-X, Tang X-J, Shi Q-L, et al. Clinical and immunological assessment of asymptomatic SARSCoV-2 infections. Nature Medicine. 2020;26(8):1200-4.

18. To KK-W, Tsang OT-Y, Leung W-S, et al. Temporal profiles of viral load in posterior oropharyngeal saliva samples and serum antibody responses during infection by SARS-CoV-2: an observational cohort study. The Lancet Infectious Diseases. 2020;20(5):565-74. 
19. Wu J, Liang B, Chen C, et al. SARS-CoV-2 infection induces sustained humoral immune responses in convalescent patients following symptomatic COVID-19. medRxiv. 2020:2020.07.21.20159178.

20. Coppola A, Annunziata A, Carannante N, et al. Late Reactivation of SARS-CoV-2: A Case Report. Frontiers in Medicine. 2020;7(531).

21. Luciani M, Bentivegna E, Spuntarelli V, et al. Recurrent COVID-19 pneumonia in the course of chemotherapy: Consequence of a weakened immune system? J Med Virol. 2020.

22. Alizargar J. Risk of reactivation or reinfection of novel coronavirus (COVID-19). J Formos Med Assoc. 2020;119(6):1123.

23. Poland GA, Ovsyannikova IG, Kennedy RB. SARS-CoV-2 immunity: review and applications to phase 3 vaccine candidates. The Lancet.

24. The COVID-19 diagnosis and treatment flowchart in Iran (3rd edition) [Internet]. 2020 [cited 18 March, 2020]. Available from: http://treatment.sbmu.ac.ir/index.jsp? siteid=62\&fkeyid=\&siteid=62\&pageid=63989.

25. Parry J. Covid-19: Hong Kong scientists report first confirmed case of reinfection. BMJ. 2020;370:m3340.

26. Lab confirms first case of coronavirus reinfection in the US [Internet]. 2020. Available from: https://www.livescience.com/coronavirus-reinfection-case-confirmed-us.html.

27. Bonifácio LP, Pereira APS, Araújo DCdAe, et al. Are SARS-CoV-2 reinfection and Covid-19 recurrence possible? a case report from Brazil. Revista da Sociedade Brasileira de Medicina Tropical. 2020;53.

28. Nachmias V, Fusman R, Mann S, et al. The first case of documented Covid-19 reinfection in Israel. IDCases. 2020;22:e00970-e.

29. Prado-Vivar BaB-W, Monica and Guadalupe, Juan Jose and Marquez, Sully and Gutierrez, Bernardo and Rojas-Silva, Patricio and Grunauer, Michelle and Trueba, Gabriel and Barragan, Veronica and Cardenas, Paul. COVID-19 Re-Infection by a Phylogenetically Distinct SARS-CoV-2 Variant, First Confirmed Event in South America.

30. Iwasaki A. What reinfections mean for COVID-19. The Lancet Infectious Diseases.

31. Tillett RL, Sevinsky JR, Hartley PD, et al. Genomic evidence for reinfection with SARS-CoV-2: a case study. The Lancet Infectious Diseases.

32. To KK-W, Hung IF-N, Ip JD, et al. COVID-19 re-infection by a phylogenetically distinct SARScoronavirus-2 strain confirmed by whole genome sequencing. Clinical Infectious Diseases. 2020.

33. Coronavirus reinfections: three questions scientists are asking [Internet]. Nature. 2020. Available from: https://www.nature.com/articles/d41586-020-02506-y.

34. Lancman G, Mascarenhas J, Bar-Natan M. Severe COVID-19 virus reactivation following treatment for B cell acute lymphoblastic leukemia. Journal of Hematology \& Oncology. 2020;13(1):131.

35. Bentivegna E, Sentimentale A, Luciani M, et al. New IgM seroconversion and positive RT-PCR test after exposure to the virus in recovered COVID-19 patient. J Med Virol. 2020. 
36. A new Covid variant has been discovered in Brazil - here's what we know so far [Internet]. CNBC. 2021 [cited 2021/01/19]. Available from: https://www.cnbc.com/2021/01/15/brazil-a-new-covidvariant-has-been-discovered-heres-what-we-know-so-far.html.

37. Grubaugh ND, Hanage WP, Rasmussen AL. Making Sense of Mutation: What D614G Means for the COVID-19 Pandemic Remains Unclear. Cell. 2020;182(4):794-5.

38. Hu J, He C-L, Gao Q-Z, et al. D614G mutation of SARS-CoV-2 spike protein enhances viral infectivity. bioRxiv. 2020:2020.06.20.161323.

39. Lorenzo-Redondo R, Nam HH, Roberts SC, et al. A Unique Clade of SARS-CoV-2 Viruses is Associated with Lower Viral Loads in Patient Upper Airways. medRxiv. 2020:2020.05.19.20107144.

\section{Tables}

\begin{tabular}{|c|c|c|c|}
\hline \multicolumn{2}{|c|}{ GACCCCAAAATCAGCGAAATG } & N1F primer & \multirow[t]{2}{*}{$\mathrm{N}$ gene } \\
\hline \multicolumn{2}{|c|}{ TGTAGCACGATTGCAGCATTG } & N3R primer & \\
\hline \multicolumn{2}{|c|}{ TCAGACAAATCGCTCCAGGG } & Zabih OF & \multirow[t]{2}{*}{ S gene } \\
\hline \multicolumn{2}{|c|}{ AGCAACTGAATTTTCTGCACCA } & Zabih OR & \\
\hline Number of cycles & Duration & Temp. & \multirow[t]{10}{*}{ PCR program } \\
\hline \multirow[t]{5}{*}{8} & $20 \mathrm{~min}$ & $50^{\circ} \mathrm{C}$ & \\
\hline & $2 \mathrm{~min}$ & $95^{\circ} \mathrm{C}$ & \\
\hline & $15 \mathrm{~s}$ & $95^{\circ} \mathrm{C}$ & \\
\hline & $20 \mathrm{~s}$ & $65^{\circ} \mathrm{C}$ & \\
\hline & $1 \mathrm{~min}$ & $72^{\circ} \mathrm{C}$ & \\
\hline \multirow[t]{4}{*}{35} & $15 \mathrm{~s}$ & $95^{\circ} \mathrm{C}$ & \\
\hline & $20 \mathrm{~s}$ & $58^{\circ} \mathrm{C}$ & \\
\hline & $1 \mathrm{~min}$ & $72^{\circ} \mathrm{C}$ & \\
\hline & $5 \mathrm{~min}$ & $72^{\circ} \mathrm{C}$ & \\
\hline
\end{tabular}


Table 2. Covid-19 re-infected/reactivated cases characteristics.

\begin{tabular}{|c|c|c|c|}
\hline Cases & No.1 & No. 2 & No.3 \\
\hline Gender & Female & Male & Male \\
\hline Age & 32 & 54 & 42 \\
\hline First infection & $2020 / 04 / 20$ & $2020 / 04 / 04$ & $2020 / 03 / 10$ \\
\hline PCR test & $\mathrm{N} / \mathrm{A}$ & + & + \\
\hline$N C t^{*}$ & $\mathrm{~N} / \mathrm{A}$ & 27 & $\mathrm{~N} / \mathrm{A}$ \\
\hline ORF Ct & $\mathrm{N} / \mathrm{A}$ & 29 & $\mathrm{~N} / \mathrm{A}$ \\
\hline $\lg M$ & + & + & $N / A^{*}$ \\
\hline $\lg G$ & - & + & $\mathrm{N} / \mathrm{A}$ \\
\hline Second infection & $2020 / 07 / 17$ & $2020 / 08 / 22$ & $2020 / 07 / 04$ \\
\hline PCR test & + & + & + \\
\hline$N C t$ & 17 & 29 & 31 \\
\hline ORF Ct & 18 & 30 & 33 \\
\hline $\lg M$ & - & - & + (rapid test) \\
\hline $\lg G$ & + & + & + \\
\hline \multirow[t]{2}{*}{ IgG titration } & 2020/07/20: 4.89 & 2020/08/23: 5.25 & 2020/07/21: 17.5 \\
\hline & 2020/09/02: over & 2020/09/08: 27.5 & 2020/09/06: 6.5 \\
\hline $\begin{array}{l}\text { lgG assessment } \\
\text { post infection } \\
\text { onset }\end{array}$ & 3 days & 1 day & 17 days \\
\hline Infection interval & 63 days & 156 days & 111 days \\
\hline $\begin{array}{l}\text { Primary clinical } \\
\text { symptom }\end{array}$ & $\begin{array}{l}\text { Headache, sore } \\
\text { throat, cough, } \\
\text { fever }\end{array}$ & $\begin{array}{l}\text { Fatigue, anxiety, chest } \\
\text { pain, cough, fever }\end{array}$ & $\begin{array}{l}\text { Shortness of breath, sore throat, } \\
\text { shaking chills, pain, diarrhea }\end{array}$ \\
\hline $\begin{array}{l}\text { Secondary clinical } \\
\text { symptom }\end{array}$ & $\begin{array}{l}\text { Severe cough, } \\
\text { fever, fatigue }\end{array}$ & $\begin{array}{l}\text { Milder fatigue, chest } \\
\text { pain, dizziness, } \\
\text { diarrhea }\end{array}$ & $\begin{array}{l}\text { Similar to the first infection with } \\
\text { severe diarrhea }\end{array}$ \\
\hline $\begin{array}{l}\text { Sequencing } \\
\text { finding }\end{array}$ & D614G mutation & $\begin{array}{l}\text { L139L non- } \\
\text { synonymous mutation }\end{array}$ & D614G mutation \\
\hline \multicolumn{4}{|l|}{ N/A: Not applicable } \\
\hline${ }^{*}$ Ct: Cycle threshold & & & \\
\hline
\end{tabular}


Figures

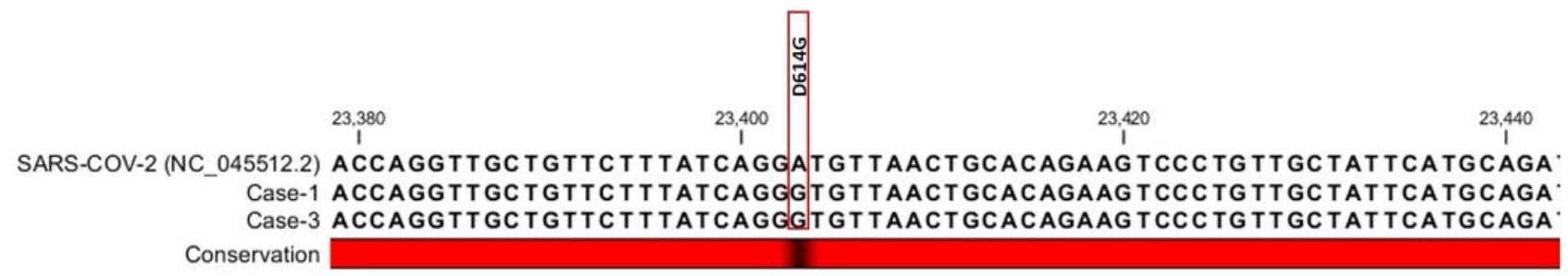

\section{Figure 1}

Alignment of partial S gene of cases No\#1 and \#2 in the second infection. 


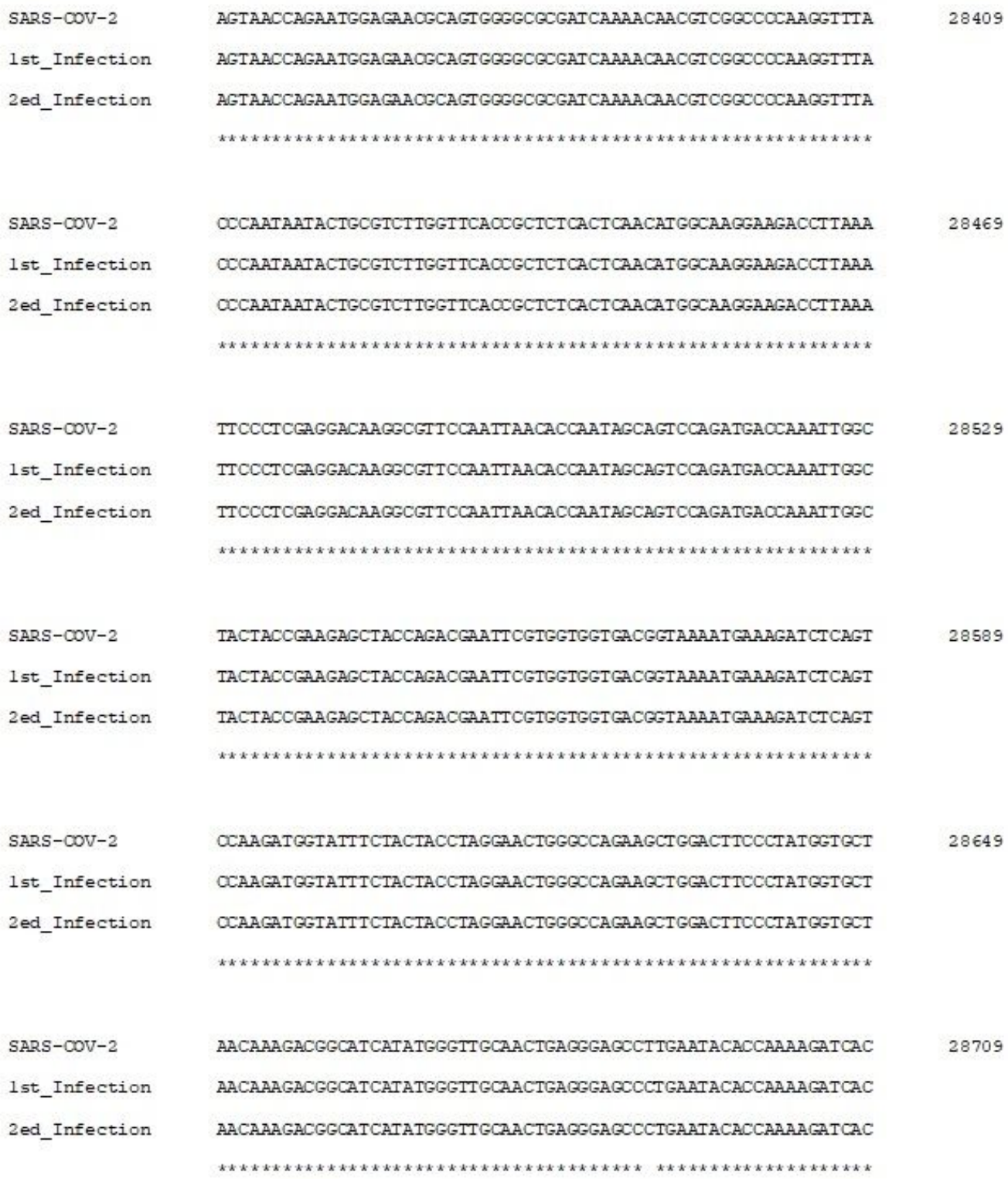

\section{Figure 2}

Alignment of partial $\mathrm{N}$ gene of case No\#2 in two episodes of infection. The sequences of first and second infections are identical even at c.28688 T>C (p.L139L). 